\title{
INDUSTRIAL ELECTRON BEAM INSTALLATION L-8 FOR DEPOSITION OF HEAT-PROTECTIVE COATINGS ON TURBINE BLADES
}

\author{
N.I. GRECHANYUK, P.P. KUCHERENKO, A.G. MELNIK, D.V. KOVALCHUK and I.N. GRECHANYUK ${ }^{*}$ \\ $\mathrm{SPE} \ll$ Eltechmach» Ltd.» \\ 25 Vatutin Str., Vinnitsa, Ukraine. E-mail: eltechmach@gmail.com
}

\begin{abstract}
The electron beam technologies find ever wider application in the world in production and repair of turbine blades. Equipment for their realization is manufactured in Germany, USA, Ukraine and other countries. The work describes the design features and technological capabilities of industrial electron beam installation L-8 for deposition of heat-protective coatings on turbine blades, designed at the scientific and production enterprise «Eltechmach». The distinguishing feature of the installation is its capability to deposit all the modern heat-protective coatings in the one type of equipment and, if necessary, for one technological cycle. The problem of preheating of blades in lock chambers of the installation, their ion cleaning before deposition of heat-protective coating, and also formation of barrier microlayers between functional layers of heat-protective coatings was solved to delay the diffusion processes at their interfaces and to control the thickness of heat-protective coatings. 14 Ref., 3 Figures.
\end{abstract}

$\boldsymbol{K} \boldsymbol{e} \boldsymbol{y} \boldsymbol{w} \boldsymbol{o r d} \boldsymbol{s}:$ electron beam installation, heat protective coatings, gas turbine blades

At the present time a special attention is paid to the creation of specialized electron beam equipment for deposition of heat-protective coatings (HPC) on turbine blades. Among the leading world producers are the companies ALD Vacuum Technologies, Von Ardenme, Pratt\&Whitney, the E.O. Paton Electric Welding Institute of the NAS of Ukraine, etc. In particular, a number of industrial EB installations for deposition of HPC was manufactured by PWI and successfully operate [1-4]. The general feature of these installations is application of flat-beam electron guns with the service life of cathode of not more than $50 \mathrm{~h}$.

The certain achievements in creation of the similar equipment were attained at the SPE «Eltechmach» [5-13].

The distinguishing feature of industrial EB installation L-8, designed by «Eltechmach», is the application of gas-discharge guns and possibility of deposition of all types and designs of protection coatings: metallic, ceramic, composite, cermet, single-layer, multilayer, gradient, etc. The HPC, complicated by their chemical composition and design, can be formed on the gas turbine blades in the given installation for one technological cycle.
Technical data of industrial EB installation L-8 Dimensions of cylindrical cassette with products, $\mathrm{mm}$, not more than:

diameter .................................................. 250

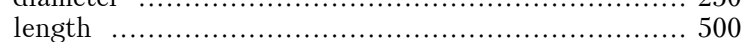

Speed of product rotation at the horizontal

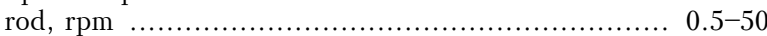

Number of evaporators, pcs .................................... 4

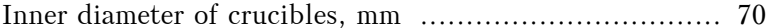

Length of ingots being

evaporated, $\mathrm{mm}$............................ not more than 500

Speed of ingots feeding, $\mathrm{mm} / \mathrm{min} \ldots \ldots \ldots \ldots \ldots \ldots \ldots . . . . . .50 .5-350$

Distance from the upper cut of crucibles to axis

of cassette rotation or plane of spraying, $\mathrm{mm}$.............. 350

Number and rated power $(\mathrm{kW})$ of electron guns:

for evaporation of materials from crucibles ......... $4 \times 100$

for heating of products ........... $2 \times 60$

Type of electron guns - axial with cold cathode

(on the base of high-voltage glowing discharge)

Consumed power, $\mathrm{kW}$, not more than:

by high-voltage power sources .......................... 520

by auxiliary equipment $\ldots \ldots \ldots \ldots \ldots \ldots \ldots$

Rated accelerating voltage, $\mathrm{kV}$......................... 30

Working vacuum in chambers, $\mathrm{Pa}$

( $\mathrm{mm} \mathrm{Hg}$ )

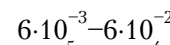

$\left(5 \cdot 10^{-5}-5 \cdot 10^{-4}\right)$

Dimensions of installation, $\mathrm{mm}$, not more than:

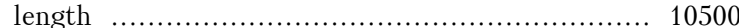

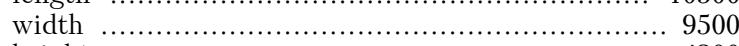

height ................... 4300

Mass of installation (with power

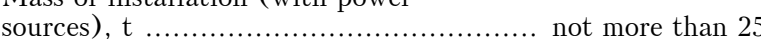

The general view of the installation is given in Figure 1.

The installation represents the unit of vacuum chambers with mechanisms, devices and systems providing performance of technological process of deposition of coatings in vacuum. The scheme of chamber for deposition of coatings is given in

\footnotetext{
${ }^{*}$ V.I. Melnik, I.V. Melnik and B.A. Tugaj participated in this work. 

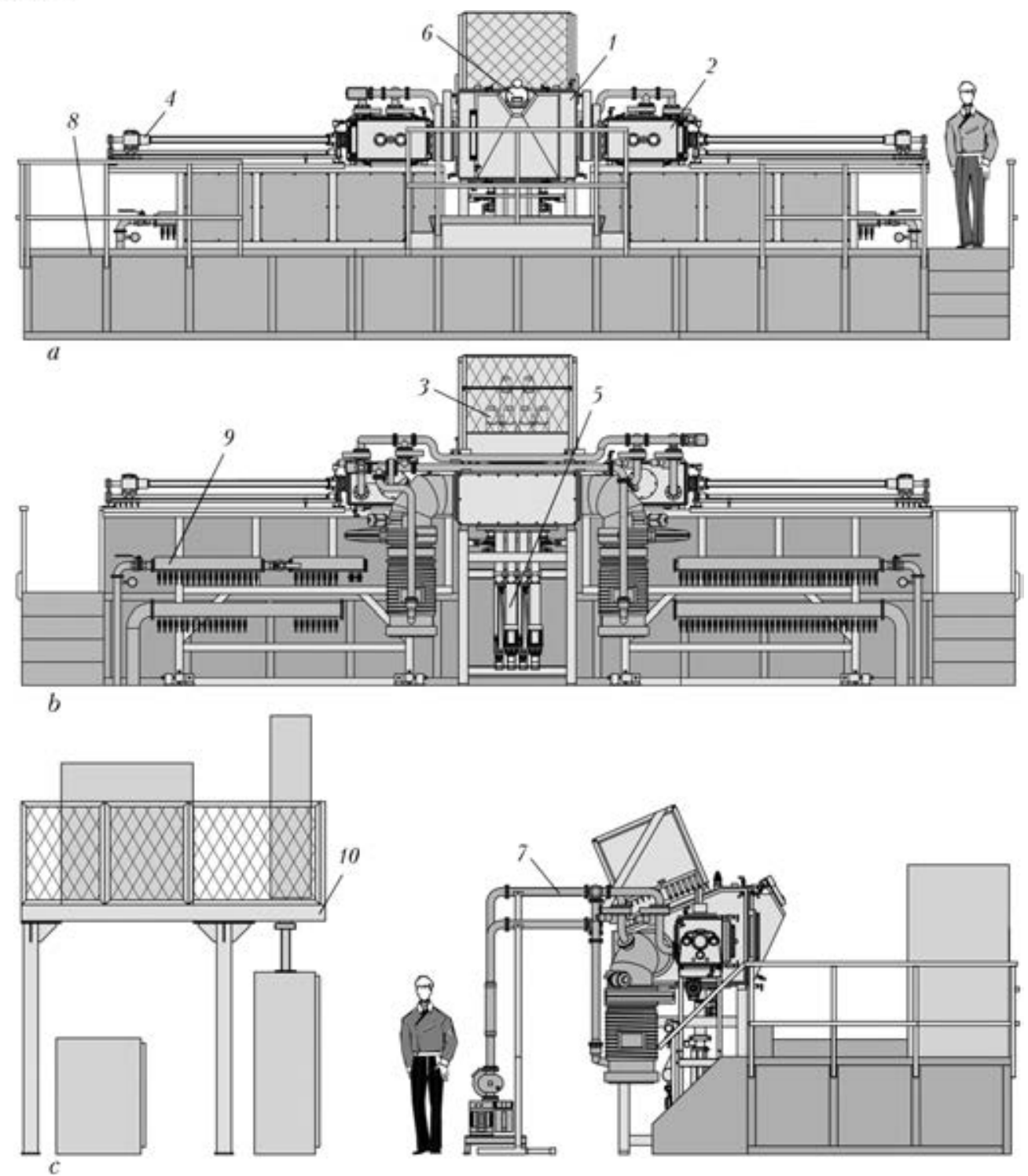

Figure 1. General view of installation L-8: $a$ - front view; $b-$ back view; $c-$ left view; $1-$ technological chamber; 2 - lock chamber; 3 - electron guns; 4 - mechanism of cassette (products) feeding; 5 - mechanism of ingot feeding; 6 - sight system; 7 - vacuum system; 8 - service area; 9 - cooling system; 10 - platform of high-voltage power sources

Figure 2. The appearance of the installation is given in Figure 3.

In the technological (working) chamber of installation (see Figure 2) the process of deposition of vapor flow on the billets, being coated, occurs. In working chamber the vacuum of $5 \cdot 10^{-5}-5 \cdot 10^{-4} \mathrm{~mm} \mathrm{Hg}$ is maintained. Below the chamber the unit of evaporators is attached, in the composition of which four copper watercooled crucibles and four mechanisms for feeding the evaporating ingots are included. The loading of ingots of evaporating materials into the mechanisms is performed atop through the crucibles. The electron guns are mounted on the upper cover of working chamber.

Two synchronically operating gates are designed for screening of parts being coated during initial heating of evaporating materials and parts before setting up of stable technological mode of evaporation. Two other gates, mounted in the working chamber, serve for protection of shutters, dividing the lock and working chambers, from dusting and high temperature during carrying out of technological process.

On the upper wall of chamber the sensor for control of thickness of depositing coatings is mounted, and on the back wall - ball input with sight tube and peephole for the possibility of contact-free measurement of temperature. The measurement of temperature of products in installation is performed using high-technological infrared pyrometer and special software. The electromagnetic gas inlet valves with system of flow stabilization, providing the dosing inlet of technological gases, are mounted on technological and loading chambers. 

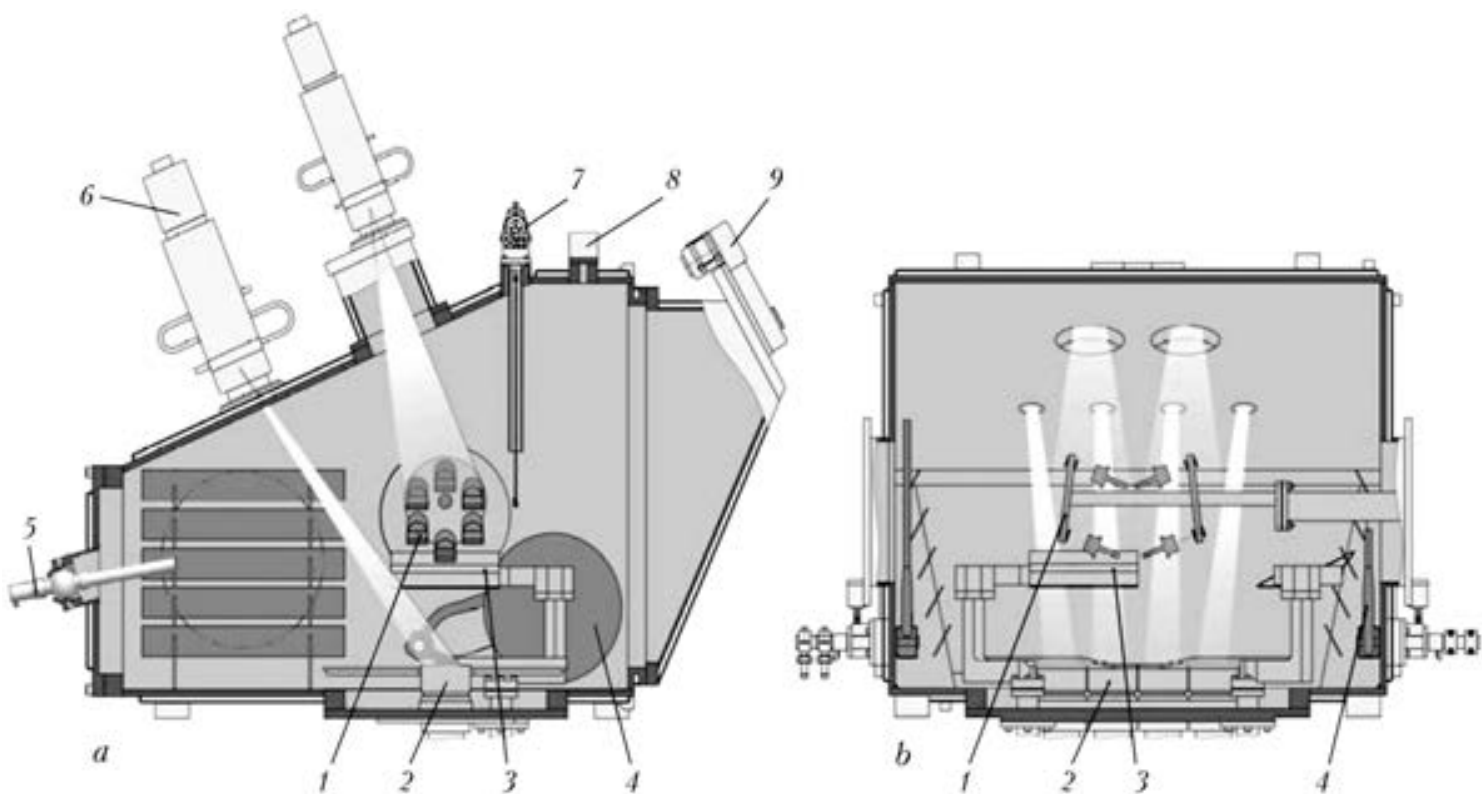

Figure 2. Scheme of technological chamber of installation: $a$ - transverse section; $b$ - longitudinal section; $1-$ cassette with blades; 2 - crucibles; 3 - gates of evaporators; 4 - gates of shutters; 5 - ball input for mounting of pyrometer; 6 - electron gun; 7 - weighing sensor; 8 - inlet valve for technological gas; 9 - sight system

The adding of low amount of gas (argon) to the process of evaporation results in dispersion of vapor flow, which allows performing the more uniform deposition of material to open and shadow areas of the product [3].

In the installation the capability to perform a partial ionization of technological gas and metal vapor by supply of negative potential (up to $2 \mathrm{kV}$ ) to the products is also envisaged. The ionization facilitates the producing of coating with favorable structure without crystallographic defects, which arise in the condensed layer during inlet of gas [14].

The possibility of oxygen supply to the chamber during deposition of ceramics to provide its stoichiometric composition is also envisaged.

The lock chambers are designed for reloading of the products being coated. Separation of volumes of the chambers mentioned-above is carried out by two vacuum shutters of $d=320 \mathrm{~mm}$. The presence of two auxiliary chambers increases the installation efficiency. The deposition of coatings on the products, supplied one by one from the lock chambers, is occurred without evacuation of technological chamber.

In the lock chambers of installation the possibility to carry out the ion cleaning of products before deposition of coatings is envisaged, which allows improving the adhesion of deposited layer with a part, and also depositing barrier microlayers between the functional layers of HPC with the purpose of delaying the diffusion processes at their boundaries. For this purpose the installation is equipped with arc evaporators, which are mounted on each loading chamber, and system for the control of ion cleaning. In the control cabinet the power sources of arc evaporators and two adjustable sources of bias voltage are located, which is supplied to the rigging with products in the process of cleaning. Thus, the cleaning

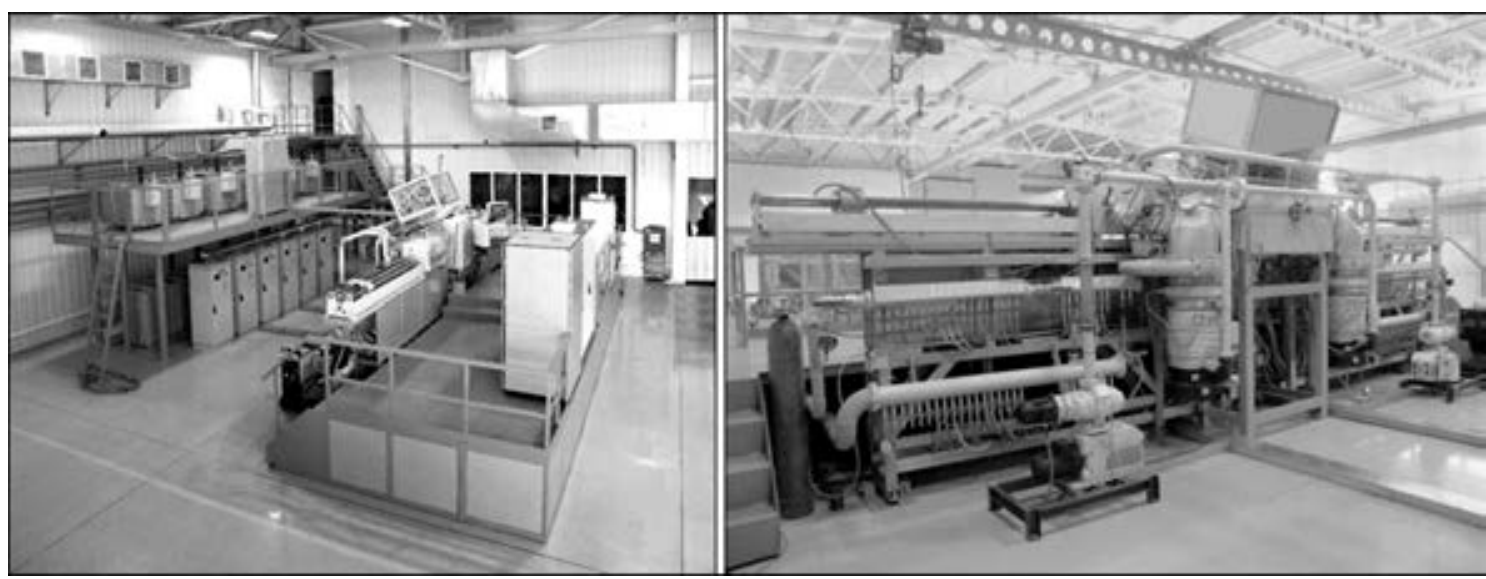

Figure 3. Appearance of EB installation L-8 
can be performed in two modes: preliminary degassing and cleaning of products by glowing discharge in argon by supply of negative potential of up to $2 \mathrm{kV}$ to the rigging with products relatively to the chamber casing, and cleaning by bombardment of parts with ions of metal using arc evaporator and supply of bias voltage to the rigging.

As the cathode the alloy CrLaFe is used in evaporator. As a result of burning of arc discharge in vacuum the ionization and spraying of cathode material occurs. The control of bias voltage at the products allows changing the rate of deposition of sublayer and temperature of heating of parts as a result of bombardment.

The mechanisms of horizontal feeding of products serve for movement of sprayed products from pre-chambers to working chamber and vice-versa and also for rotation of rigging with products. To compensate the possible deflection of rod in the extreme protruded position the front support of rod is made on pivots.

The introduction of horizontal rod to the chamber is performed so that the tightening of advancing and rotational movement of rod is performed by different tightening devices. Such a cross coupling prevents a quick coming out of order of a cup-type seal of advancing rod movement. The rods are equipped with current collector to supply the bias voltage through the hollow shaft to rigging with products. The bias voltage of up to $2 \mathrm{kV}$ is required to perform the ion cleaning of products.

The vacuum system of the installation is designed using the completing parts of Oerlikon Leybold Vacuum (Germany) and VAT (Switzerland). The shutters and valves with pneumatic drive are used. During switching-off of electric power or drop in pressure of the compressed air all the valves and shutters are automatically closed under the action of built-in springs. The forevacuum pumps are characterized with low level of noise and are completed with filters for purification of exhausted fumes. The Roots pump has a built-in valve of protection against the excessive drop of pressure at inlet and outlet and allows beginning of pumping-out at the atmospheric pressure at inlet simultaneously with switching-on of the forevacuum pump. As a result, the speed of pumping of pumps combination is increased. The oil-vapor pumps are supplied with vapor catching trap and have built-in thermostats for protection against the oil overheating and exceeding of cooling water temperature.

The system of vacuum control provides the automatic emergency closing of shutters of high- vacuum pumps during drop of vacuum in the chambers below $10^{-1} \mathrm{~mm} \mathrm{Hg}$ and also emergency stoppage of pipelines during pumping of mechanical pumps at sudden interruption of power supply.

The direct control of vacuum system is performed in automatic or manual mode using sensor panel of operator, which has a separate control window for this purpose. The information about the state of vacuum in main pipelines of vacuum system, pumps, chambers, etc. is displayed on the operator panel. To measure vacuum in the installation the vacuum gauges with output signal proportional to pressure are used. All measuring signals from vacuum meters are processed using industrial controller and displayed on the operator panel. The cooling system of the installation provides supply of cold water to the units and assemblies requiring cooling. The flow of water through the most critical units (crucibles, pumps, guns) is controlled using flow sensors. The temperature of cooling water is also controlled. When flow is absent or the preset value of temperature is exceeded, the protective switching-off of accelerating voltage sources is operated. Information about the water presence or absence is displayed on the screen of operator.

The sight system located on the front door of technological chamber represents a stroboscopic device for monitoring the surface of molten ingots in crucibles and heating of products.

Four EB guns of $100 \mathrm{~kW}$ power are installed for evaporation of materials from crucibles in such a way that each gun, designed for evaporation of ingot from the certain crucible, can also evaporate the material from the neighboring crucible. To heat the products, two guns of $60 \mathrm{~kW}$ power are used.

In the installation the gas-discharge EB guns are applied.

Technical parameters of EB guns of $100 \mathrm{~kW}$ power

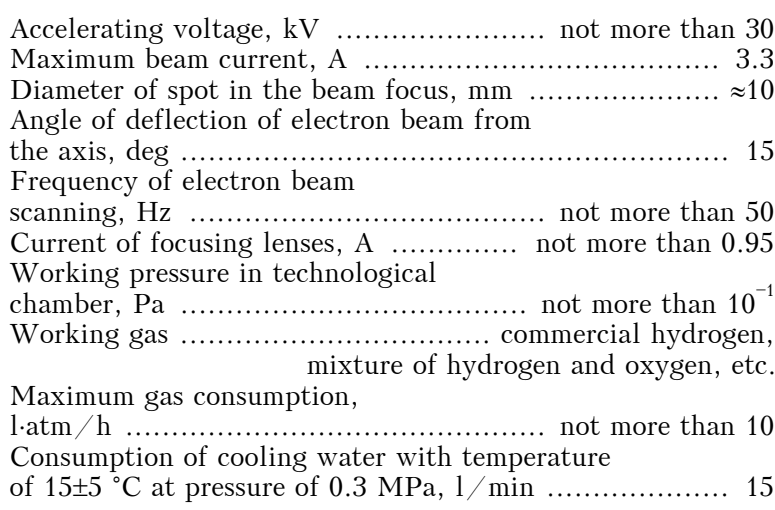

The use of cold cathode of low-alloyed aluminium alloy excludes any its distortion, which 
provides a stable electron beam. The total life of cathode amounts to about $1000 \mathrm{~h}$. The use of electromagnetic focusing system in the guns with cold cathode provides a quality beam with minimum diameter of focal spot of about $10 \mathrm{~mm}$.

The principle of operation of gas-discharge gun is based on generating and formation of electron beam in high-voltage glowing discharge. During operation of the gun the high-voltage glowing discharge with plasma is burning in its discharge chamber (between cathode and anode), being localized near the anode and separated from the cathode by the area of cathode potential drop. Plasma emits positive ions, which are accelerated by the field in the area of cathode drop and bombard the cathode, causing the emission of electrons. The field of cathode potential drop accelerates the electrons and forms the converging electron beam with the crossover, located at the distance from cathode close to the radius of curvature of its emission surface (near the hole in anode).

The magnetic field, generated by the first focusing lens, forms an electron beam close to cylinder by its shape, and due to this it passes through the beam conductor to the technological chamber without power losses. Using the second focusing lens the beam is focused on the surface of melt and with the use of deflection systems the program beam scanning is performed.

The control of discharge current is provided by control of pressure of working gas in the gun at its continuous pumping-out together with technological chamber of the installation. For effective control of discharge current and stabilization of operation mode of gun the system of automatic inlet of gas is used.

The system for control of EB guns provides control and stabilization of beam currents, currents of electromagnetic lenses, control of position and scanning of beam, and also allows performing deposition of laminar (microlaminar) coatings.

The installation consists of six high-voltage power sources to supply six EB guns with direct current of high voltage. High-voltage power source provides conversion of three-phase alternating voltage to the direct voltage, limitation of short circuiting currents, switching-off of high voltage during breakdowns in guns, and also automatic repeated switching-on.

One set of high-voltage power source includes the following components: cabinet of startingprotection equipment, current-limiting choke, and high-voltage transformer.

High-voltage converter is composed of power high-voltage transformer, rectifier unit and highvoltage dividers placed into one oil-filled body.
The system of electric drive control provides control of mechanisms of ingots feed, mechanisms for feed and rotation of side shafts, sight system, crucible gates and gates of interchamber shutters.

The motors of mechanisms for feed of ingots are equipped with encoders, the output signal of which is supplied to the frequency converters and used to stabilize and widen the range of ingots feed speed control.

The signals from encoders on the mechanisms for feeding ingots and feeding of side shaft are also used by the system on the base of PLC for positioning and measuring of feed speeds of the mentioned mechanisms. The setting of zero values of rod position is performed automatically during response of end switches. The position of mechanisms and speed of shaft rotation are displayed on the screen of operator.

The system of control of side shafts feeding allows performing the reciprocal movement of rigging with products in the process of coating deposition in the preset limits and at the preset speed to provide uniformity of coatings, being deposited, around the perimeter of products.

The automated system for control and monitoring of technological parameter provides automatic acquisition and visualization of technological parameters in real time, documentation of information in the database, performance of functions of automatic and manual control of vacuum system of the installation.

The complex is composed of two main systems: system of control, acquisition, processing and visualization of technological information on the base of industrial program controller and sensor panel of operator, and information-recording system on the base of industrial computer with the operational system Windows ${ }^{\circledR}$.

The software of the sensor panel of operator was developed in the form of multiwindow interface. In the window «Symbolic Circuit» the symbolic circuit of all the vacuum system with display of digital values of vacuum in seven points according to received data from the control system is presented. The system for control of vacuum pumping-out gives operator a possibility to work in manual, automatic and service modes.

In manual mode the operator is given a possibility to control the vacuum equipment on his own discretion. In this mode the control system puts into operation the program lockups, which do not allow operator to carry out incorrect actions as to the vacuum system. Moreover, only those control elements are displayed on the symbol circuit, with the help of which the actions 
can be performed, and those become unavailable which are dead.

During switching to the automatic mode a block of buttons appears on the screen, which are used to perform functions of automatic pumping-out of vacuum chambers, inlet of air and also switching-off the installation after finishing of work and return of vacuum system to the initial state. The mode «Service» releases all the lockups and is used only for setting-up the system of management of engineering workers attending the installation. To activate the mentioned mode it is necessary to enter the access password.

In the window «Process» the values of accelerating voltages, beam currents of electron guns, speed of feeding ingots and their remnants, value of vacuum in the working and loading chambers, position of horizontal shafts, values of weighing sensor, temperature of product, presence of water flow in the cathodes and anodes of electron guns and crucibles, etc. are displayed.

The windows «Vacuum diagrams», «Temperature diagram» and «Beam currents» present the possibility of observation of the change of mentioned parameters in real time.

The efficiency of the installation is up to 60,000 coated blades per year. The installation passed successfully the industrial tests and is put into industrial service at SPA «Saturn» (Rybinsk, RF).

\section{Conclusions}

1. The design was developed, electron beam installation L-8 for deposition of HPC on the gas turbine blades was manufactured and successfully put into industrial service.

2. The problem of preheating of blades in the lock chambers of the installation, their ion cleaning before deposition of HPC, and also formation of barrier microalloys between the functional layers of HPC to delay the diffusion processes at their interfaces was solved.

3. The problem of thickness control in the process of HPC deposition was solved.
1. Pap, P.A., Malashenko, I.S., Ivanov, A.M. (1975) Laboratory installation for producing of protective coatings of different purposes by electron beam vacuum condensation. Spets. Elektrometallurgiya, Issue 27, 98-104.

2. Chvertko, A.I. Shcherbitsky, V.V. Movchan, B.A. et al. (1982) Commercial electron beam installation UE-175M for deposition of protective coatings on gas turbine blades. Ibid., Issue 50, 53-61.

3. Movchan, B.A., Malashenko, I.S. (1983) Heat-resistant vacuum-deposited coatings. Kiev: Naukova Dumka.

4. Movchan, B.A., Yakovchuk, K.Yu. (2004) Electron beam installations for evaporation and deposition of inorganic materials and coatings. Advances in Electrometallurgy, 2, 9-14.

5. Grechanyuk, N.I., Kucherenko, P.P., Osokin, V.A. et al. (2000) State-of-the-art and prospects of producing of thermal barrier coatings for gas turbine blades and equipment for their deposition. Novyny Energetyky, 9, 32-37.

6. Grechanyuk, N., Kucherenko, P., Osokin, V. et al. (2013) New materials, coatings and electron-beam equipment for their production. In: Proc. of Int. Conf. on Electron Beam Technologies (Varna, Bulgaria, 2013), 258-264.

7. Grechanyuk, N., Kucherenko, P. Installation for coating parts using electron beams. Pat. 2451682 Canada. Publ. 23.05.2005.

8. Grechanyuk, N., Kucherenko, P. Installation for electron-ray coatication of coatings. Pat. 6923868 B2 US. Publ. 2.08.2005.

9. Grechanyuk, N.I., Kucherenko, P.P. Installation for electron beam deposition of coatings. Pat. 2265078 RF. Introd. 27.11.2005.

10. Grechanyuk, N., Kucherenko, P., Grechanyuk, I. et al. (2006) Modern technologies and equipment for obtaining of new materials and coatings. In: Proc. of 8th Int. Conf. on Electron Beam Technologies (5-10 June, 2006, Varna, Bulgaria), 122-128.

11. Grechanyuk, N.I., Kucherenko, P.P., Grechanyuk, I.N. (2007) New electron beam equipment and technologies of producing advanced materials and coatings. The Paton Welding J., 5, 25-29.

12. Grechanyuk, N., Medzinski, B., Grodzinski, A. (2010) Modern electron beam technologies for fabrication of various materials, powders and metal compositions from a vapour phase. Przeglad Elektrotechniczny, 5, 1-4.

13. Grechanyuk, N., Melnik, A., Grechanyuk, I. et al. (2014) Modern electron beam technologies and physical vapor deposition of different materials. In: Proc. of 11th Int. Conf. on Electron Beam Technologies (8-12 June, 2014, Varna, Bulgaria), 115-121

14. Boone, D.H., Lee, D., Shafer, J.M. (1977) The electron beam coating of turbine components and ion plating. In: Proc. of Conf. on Ion Plating and Allied Technologies (Edinburgh), 141-148.

Received 01.09.2014 